\title{
Stability analysis of semi-trimaran flat hull ship for a sea transportation model
}

\author{
Gerry Liston Putra*, Hadi Tresno Wibowo, Fendra Agusta \\ Universitas Indonesia, Depok, 16424, Indonesia
}

Article history:

Received: 10 August 2017 / Received in revised form: 24 October 2017 / Accepted: 10 November 2017

\begin{abstract}
Indonesia as an archipelagic nation highly requires a model of sea transportation as interconnection mainframe between islands. An effective and efficient use of sea transportation is the main factor to improve Indonesian economy. Therefore, it is necessary to optimize the sea transportation model that services throughout Indonesian sea. It has been known that an alternative solution to this specific need is the use of Semi Trimaran Flat Hull Ship. The main supporting reason is the good stability feature owned by this ship design. The focal point of this research is to evaluate the stability test using inclining method according to international standard. Maximum righting lever (GZ) obtained is $4.59 \mathrm{~cm}$ for the model size or $1.377 \mathrm{~m}$ for the original size in 57.3 degrees. The value is greater than 25 degrees as a standard value. Thus, the result of ship stability analysis shows that semi-trimaran Flat Hull Ship has complied with all IMO (International Maritime Organization) criteria. All of these results indicate that this ship has good stability feature and fit to be continued in a physical testing.
\end{abstract}

Keywords: Stability; Flat Hull Ship; Inclining Test

\section{Nomenclature}

B Breadth

H Depth

$T \quad$ Draft

KMt The transversal distance between Keel and Metacenter

$K M L \quad$ The longitudinal distance between Keel and Metacenter

BMt The transversal distance between Buoyancy and Metacenter

$B M L$ The longitudinal distance between Buoyancy and Metacenter

GMt The transversal metacentric height

GML The longitudinal metacentric height

$G M_{O}$ The initial metacentric height

IACS International Association of Classification Societies

IMO International Maritime Organization

$K G \quad$ The distance between Keel and Gravity center

TPC Tonnes per cm Immersion

MTc Moment to Change Trim $1 \mathrm{~cm}$

GZ Righting Lever

\section{Introduction}

Indonesia as an archipelagic nation highly requires a model of sea transportation as interconnection mainframe between islands. An effective and efficient use of sea transportation is the main factor to improve Indonesian economy. Ship as a sea

* Corresponding author.

Email: gerrylistonp@gmail.com transportation module relatively has a long manufacturing process altogether with a huge cost. Bending plate process is one of the considerable costs in the manufacturing process. Thus, it is important to reduce the manufacturing cost through an optimization of the manufacturing process.

Flat Hull Ship design is an alternative solution to reduce manufacturing cost [1]. This typical ship eliminates bending process during its manufacturing; since this typical ship consists of flat plates that can be simply joined through its process. In other words, this easier and cheaper manufacturing process compensates its overall manufacturing process in term of cost and facility.

One of the modified types of the ship with the significant improvement is semi-trimaran hull form. The typical form of semi-trimaran can be designed similarly with the water tunnel configuration. Hence, this structure facilitates the fluid to flow into the propeller and thus increases the velocity of the ship. Another benefit of this structure is to improve the stability of the ship; because this type of hull seemly has a stabilizer on its side. Ship stability is the ability of a ship to return to its original position after receiving the forces from the outside [2]. Therefore, this research is to emphasize the stability test of the Semi Trimaran hull form using inclining method according to international standard. This evaluation is important to initially support the ship model to be proposed in reducing the manufacturing cost and facility.

\section{Model and Method}

Initially, this research was conducted to examine the center 
of gravity of light ship. Inclining test is required to get the center of gravity and comply with IACS standard. Furthermore, this study uses Maxsurf as numerical computation software to provide hydrostatic and stability calculation. The concept of the study is described as shown in Fig. 1. The inclining test was evaluated through both experimental and numerical methods. The intact stability [3] can further be observed. Then, the analysis of the results can be conducted.

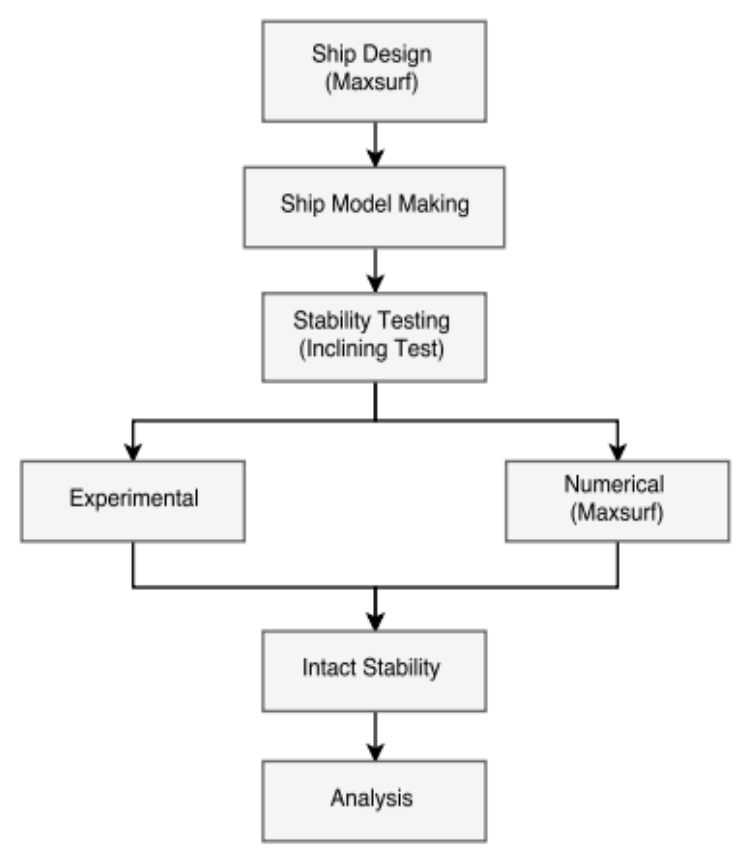

Fig. 1. Research Methods

Table 1. Ship Dimension

\begin{tabular}{lccc}
\hline & Item & Real Size & Model Size \\
\hline LOA (m) & 24 & 0.8 \\
B (m) & 7.2 & 0.24 \\
H (m) & 4.5 & 0.15 \\
T (m) & 2.6 & 0.072 \\
Scale & & $1: 30$ & \\
\hline
\end{tabular}

The main dimension used to design a ship in Maxsurf software is presented in Table 1. At the beginning, the ship was designed by linear algebra to find an exact coordinate point. This ship uses Axe Bow design and Reverse Duck Tail. This hull form is a development of Wake Equalizing Duct (WED) application designed by Schneekluth [4]. This WED consists of two semicircular duct nozzles mounted on two back sides of the ship before propeller position. It aimed to increase energy saving. This ship was designed to be similar with water tunnel; positively, this will ease the fluid to flow into propeller thus increasing the thrust of the ship.

Fig. 2 shows a hull design of Flat Hull Ship. Hull form consists of flat plates only. This typical design is easier applied than general one. It can be evaluated in detail through stability testing, i.e. inclining test using experimental and numerical methods. To test the methods, hydrostatic curve should be calculated by Maxsurf. The value of KMt was also simultaneously obtained. Inclining test procedure is according to IACS standard as detailed in table 2. Material and tools of testing consist of the ship model, load, pendulum, ship cargo, and towing tank [5].
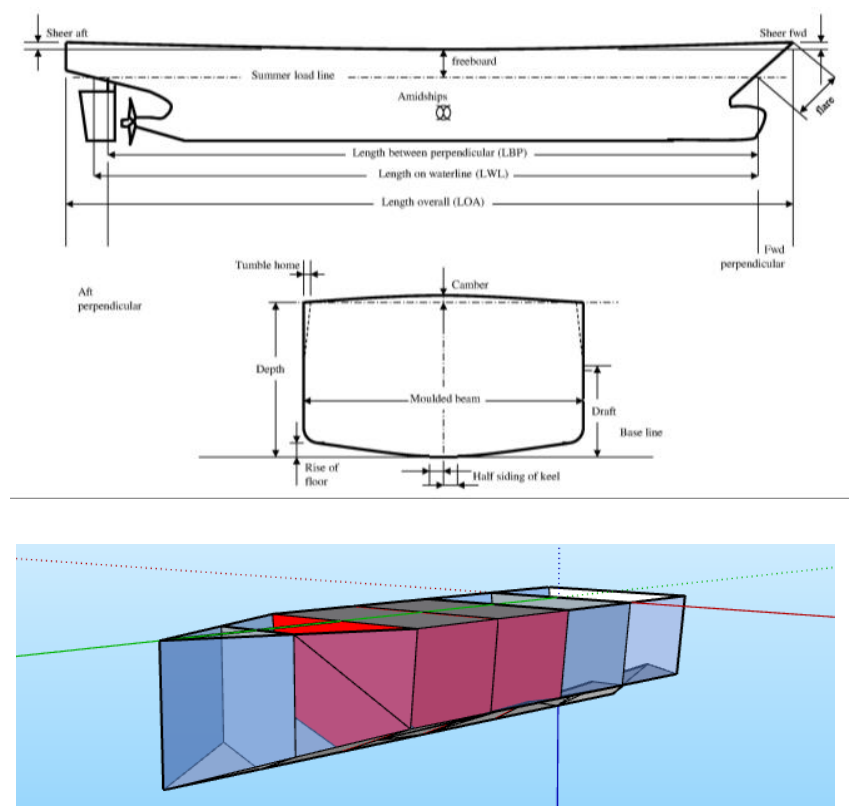

Fig. 2. Ship Design

Table 2. Movement of load procedure

\begin{tabular}{lcccc}
\hline Load Transfer & \multicolumn{4}{c}{ Number of Load } \\
\cline { 2 - 5 } Number & \multicolumn{3}{c}{ Four } & \multicolumn{3}{c}{ Six } \\
\cline { 2 - 5 } & Left & Right & Left & Right \\
\cline { 2 - 5 } No. 0 & 2,4 & 1,3 & $2,4,6$ & $1,3,5$ \\
No. 1 & 4 & $1,2,3$ & 4,6 & $1,2,3,5$ \\
No. 2 & & $1,2,3,4$ & & $1,2,3,4,5,6$ \\
No. 3 & 1 & $2,3,4$ & 6 & $1,2,3,4,5$ \\
No. 4 & 1,3 & 2,4 & $2,4,6$ & $1,3,5$ \\
No. 5 & $1,2,3$ & 4 & $1,2,3,4,6$ & 5 \\
No. 6 & $1,2,3,4$ & & $1,2,3,4,5,6$ & \\
No. 7 & $2,3,4$ & 1 & $1,2,4,6$ & 3,5 \\
No. 8 & 2,4 & 1,3 & $2,4,6$ & $1,3,5$ \\
\hline \multicolumn{2}{l}{ Left and Right show Port and Starboard side of the ship } \\
\hline
\end{tabular}

Table 2 shows the procedure for load positions. They have nine positions. In this study, we use four loads as illustrated in Fig. 3 in which the loads were positioned on the left and right topside. The inclining test was conducted to obtain the GM value. This value was used for ship stability calculation by Maxsurf software as important parameter to know the behavior of a ship.

\section{Results and Discussion}

\subsection{Inclining Test}

The hydrostatic curve [6] of the semi-trimaran flat hull ship was calculated to get KMt value before inclining test was conducted. Table 3 show a result of hydrostatic data obtained by Maxsurf software. KMt value obtained is $12.50 \mathrm{~cm}$; this was used for inclining test to know the vertical distance between the keel and metacentric point [7]. This can be 
observed in detail in Fig. 4 as transverse view of hydrostatic parameter.
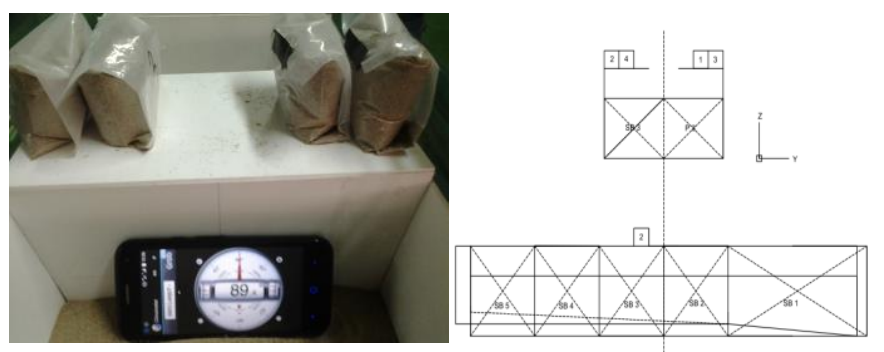

Fig. 3. Inclining Test illustration

Table 3. Hydrostatic data

\begin{tabular}{ccc}
\hline Displacement & 7.313 & $\mathrm{Kg}$ \\
Volume (displaced) & 7313.02 & $\mathrm{~cm}^{3}$ \\
Draft Amidships & 7.20 & $\mathrm{Cm}$ \\
Immersed depth & 7.22 & $\mathrm{Cm}$ \\
Beam max extents on WL & 22.81 & $\mathrm{Cm}$ \\
Wetted Area & 2198.27 & $\mathrm{~cm}^{2}$ \\
Max sect. area & 117.88 & $\mathrm{~cm}^{2}$ \\
Waterpl. Area & 1504.08 & $\mathrm{~cm}^{2}$ \\
Prismatic coeff. (Cp) & 0.775 & \\
Block coeff. (Cb) & 0.555 & \\
Max Sect. area coeff. (Cm) & 0.721 & \\
Waterpl. area coeff. (Cwp) & 0.824 & \\
BMt & 7.91 & $\mathrm{Cm}$ \\
BML & 81.77 & $\mathrm{Cm}$ \\
GMt corrected & 12.50 & $\mathrm{Cm}$ \\
GML & 86.36 & $\mathrm{Cm}$ \\
KMt & 12.50 & $\mathrm{Cm}$ \\
KML & 86.36 & $\mathrm{Cm}$ \\
Immersion (TPc) & 0.002 & tonne/cm \\
MTc & 0.000 & tonne.m \\
\hline
\end{tabular}

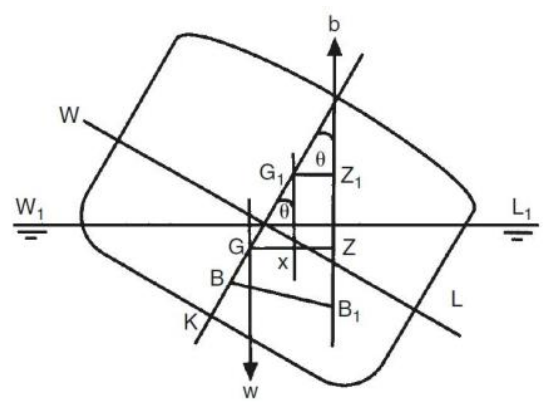

Fig. 4. Transverse view of hydrostatic parameters

The purpose of inclining test is to get the GM value [8]. GM indicates stability level of the ship [9]. Metacentric height calculation is the distance of movement center of gravity caused by moving load [10].

$$
\begin{gathered}
G G^{\prime}=\frac{w d}{\Delta} \\
G G^{\prime}=G M_{0} \tan \Theta
\end{gathered}
$$

where

$G G^{\prime} \quad=$ distance of movement center of gravity

$G M_{0} \quad=$ the initial metacentric height

$\Delta \quad=$ displacement

$d \quad=$ distance of pendulum $\ominus \quad=$ angle of the ship

$w \quad=$ load weight

Numerical inclining test has a similar procedure with experimental one. The data from Maxsurf modeler is used for Maxsurf stability input. Then, enter load is based on IACS standard. The results show that GM values obtained in average are $7.45 \mathrm{~cm}$ and $7.14 \mathrm{~cm}$ using experimental and numerical methods, respectively. The average deviation of 0.4 $\mathrm{cm}$ between experimental and numerical computation result was observed as shown in Table 4. The results at numerical condition seemly led to an ideal value; because there is no influence from the environment.

\begin{tabular}{|c|c|c|c|}
\hline \multirow{2}{*}{ Condition } & \multicolumn{2}{|c|}{ GM } & \multirow[t]{2}{*}{$\operatorname{Dev}(\%)$} \\
\hline & Experiment & Numerical & \\
\hline Cond. 0 & 7.32 & 7.11 & $3 \%$ \\
\hline Cond. 1 & 7.35 & 7.11 & $3 \%$ \\
\hline Cond. 2 & 7.6 & 7.26 & $5 \%$ \\
\hline Cond. 3 & 7.43 & 7.11 & $5 \%$ \\
\hline Cond. 4 & 7.31 & 7.11 & $3 \%$ \\
\hline Cond. 5 & 7.48 & 7.09 & $6 \%$ \\
\hline Cond. 6 & 7.65 & 7.26 & $5 \%$ \\
\hline Cond. 7 & 7.42 & 7.09 & $5 \%$ \\
\hline Cond. 8 & 7.45 & 7.11 & $5 \%$ \\
\hline Average & 7.45 & 7.14 & $4 \%$ \\
\hline
\end{tabular}

Table 4. Result of GM model

In the experimental condition, it might have an error from the environment such as wind and vibration in the towing tank. It definitely affected the experimental results in a certain manner. Level of measurement accuracy will also influence the results. It was also observed, the numerical simulation accuracy level is at $10^{-5} \mathrm{~cm}$ while experimental accuracy is at $0.1 \mathrm{~cm}$. Nevertheless, the obtained deviation between experimental and numerical methods is still below the limit of error tolerance if it is scaled to the original size. The error of GM value becomes $9 \mathrm{~cm}$ compared to that of $15 \mathrm{~cm}$ based on IACS standard [11]. GM value indicates stability level in which GM is used to be bigger than KG.

$$
K M=K G+G M
$$

where KM is the distance between Keel and Metacentric Point.

As previously the value of $\mathrm{KM}$ or $\mathrm{KMt}$ is $12.50 \mathrm{~cm}$; it means that $\mathrm{KG}$ value is $5.05 \mathrm{~cm}$. This result shows that $\mathrm{GM}$ value is much bigger than $\mathrm{KG}$ value. As shown in Fig. 4, the nearest distance gravity center to keel led to the better stability. However, GM value doesn't guarantee that ship stability is good; but the analysis intact of stability should be also evaluated as explained in the next section.

\subsection{Intact Stability}

There are some important criteria on ship stability that refers to International Maritime Organization as the following criteria [12,13]:

- The area under righting lever curve (GZ curve) shall not be less than 0.055 meter radians up to 30 degrees heeling angle

- The area under righting lever curve (GZ curve) shall not be less than 0.090 meter radians up to 40 
degrees heeling angle or the angle of down-flooding if this is less than 40 degrees

- The area under the righting lever arm curve (GZ curve) between the heeling angles of 30 degrees and 40 degrees or between 30 degrees and the angle of down-flooding, if this is less than 40 degrees, shall not be less than 0.03 meter-radians

- The righting lever GZ shall be at least $0.2 \mathrm{~m}$ at a heeling angle equal to or greater than $30^{\circ}$

- The maximum righting lever shall occur at an angle of heel not less than $25^{\circ}$

- The initial metacentric height $\mathrm{GM}_{0}$ shall not be less than $0.15 \mathrm{~m}$

When the ship tilts on any of its sides i.e. port or starboard and doesn't return back to its upright position, it is known as heeling of the vessel. Heeling is unsafe for ship, its machineries and people onboard. To avoid this condition, all IMO criteria should be achieved. The result of ship stability calculation that refers to International Maritime Organization is listed in Table 5 [14]. It was observed that all criteria on ship stability have complied with all standard criteria.

Table 5. Result of ship stability analysis

\begin{tabular}{|c|c|c|c|}
\hline \multicolumn{4}{|c|}{ Checking Stability } \\
\hline IMO Criteria & & Result & Comment \\
\hline A h $30^{\circ}(\mathrm{m} . \mathrm{rad})$ & $\geq 0.055$ & 0.476 & Accepted \\
\hline A h $40^{\circ}$ (m.rad) & $\geq 0.09$ & 1.089 & Accepted \\
\hline A h $30^{\circ}-$ A h $40^{\circ}$ (m.rad) & $\geq 0.03$ & 0.613 & Accepted \\
\hline $\mathrm{h} 30^{\circ}(\mathrm{m})$ & $\geq 0.2$ & 1.005 & Accepted \\
\hline$\varphi \mathrm{h} \max (\mathrm{deg})$ & $\geq 25^{\circ}$ & $57.3^{0}$ & Accepted \\
\hline $\mathrm{GM}_{0}(\mathrm{~m})$ & $\geq 0.15$ & 2.133 & Accepted \\
\hline
\end{tabular}

GZ value on $\mathrm{A} \mathrm{h} 30^{\circ}$, A h $40^{\circ}$, A h $30^{\circ}-\mathrm{A} \mathrm{h} 40^{\circ}$ is bigger than minimum standard of GZ value. It means that this ship is safe from heeling angle. GZ value on $\mathrm{h} 30^{\circ}$ is bigger than minimum standard of $\mathrm{GZ}$ value. It means that righting moment or the moment resulting in uprighting of the ship to its original orientation become larger. GM value is $2.133 \mathrm{~m}$; it means that increasing GM value make the ship more stable. It is reasonable because the distance of the centre of gravity and keel become smaller.

A curve in Fig. 5 shows maximum GZ $4.59 \mathrm{~cm}$ for model size or $1.377 \mathrm{~m}$ for original size in 57.3 degrees. Maximum GZ is greater than 25 degrees which have complied allowable the maximum righting lever that refers to IMO [15]. It means that the ship will be uprighting to its original orientation maximum in 57.3 degrees. We can assume that this ship has a safe angle. The result of ship stability analysis shows that semi-trimaran Flat Hull Ship has complied with all IMO criteria. This all result indicates that this ship has good stability.

\section{Conclusion}

The results of this study show that a model of semitrimaran Flat Hull Ship has a good stability which complies with IACS standard. This is one of the requirements to build the ship and seaworthy. The ship stability plays an important role in ship safety containing in IMO regulations and ensuring that this ship is safe. We have tested inclining testing and intact stability analysis which follow IACS standard and IMO criteria to ensure the good stability. Inclining test gives a GM value which is about $7.45 \mathrm{~cm}$ from experiment and $7.14 \mathrm{~cm}$ from the numerical calculation. The values show that the stability level was suitable to the requirement. Intact stability analysis shows that the maximum righting lever refers to IMO. All IMO criteria on ship stability have been achieved. It means that semi-trimaran Flat Hull Ship has good stability and is ready to be built and offering to the related stakeholder.

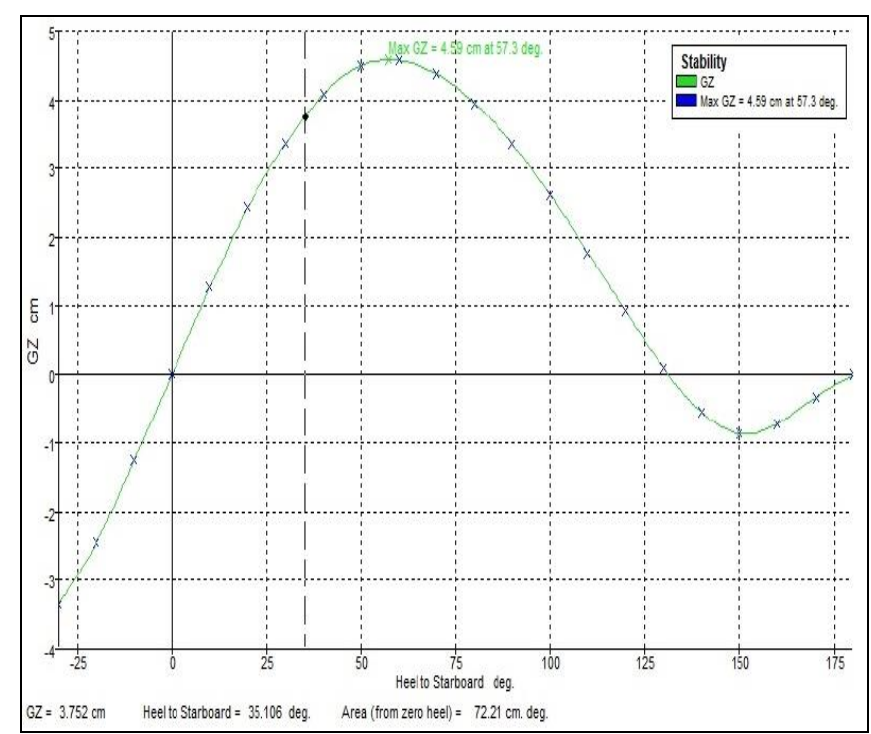

Fig. 5. Stability curve

\section{References}

1. T.W. Astiti, Revitalisasi armada pelayaran rakyat dengan menggunakan kapal baja lambung pelat datar, Undergraduate Thesis, Universitas Indonesia, Indonesia, 2015.

2. I. Bačkalov, G. Bulian, J. Cichowicz, E. Eliopoulou, D. Konovessis, J.F. Leguen, et al., Ship stability, dynamics and safety: status and perspectives from a review of recent STAB conferences and ISSW events, Ocean Engineering. 116 (2016) 312-349.

3. M.A.S. Neves, Dynamic stability of ships in regular and irregular seasan overview, Ocean Engineering. 120 (2016) 362-370.

4. E. Daniswara, Analisis karakteristik kapal model pelat datar axe bow semi-trimaran dan buritan reverse duck-tail dengan uji kecepatan berbasis remote control, Undergraduate Thesis, Universitas Indonesia, Indonesia, 2015.

5. F.A. Ayub, Perancangan alat uji inclining test berbasis IACS standard, Undergraduate Thesis, Universitas Indonesia, Indonesia, 2015.

6. A.M. Reed, A naval perspective on ship stability, 10th International Conference on Stability of Ships and Ocean Vehicles, Saint Petersburg, Russia, 2009, pp. 21-44.

7. J. King, Origins of the theory of ship stability, Transactions The Royal Institution of Naval Architects. 140 (1998) 222-238.

8. Marcus A.T. Prinsip merancang kapal. Depok, Indonesia : Teknik Perkapalan Universitas Indonesia, 2014.

9. C.B. Barrass, D.R. Derrett. Ship stability for masters and mates. Oxford, UK : Butterworth Heinemann, 2006.

10. L.G. Taylor. The principles of ship stability. Glasgow, UK : Brown, Son \& Ferguson, 1968.

11. M.D. Woodward, M.V. Rijsbergen, K.W. Hutchinson, and A. Scott, 
Uncertainty analysis procedure for the ship inclining experiment, Ocean Engineering. 114 (2016) 79-86.

12. A. Francescutto, Intact stability criteria of ships - past, present and future, Ocean Engineering. 120 (2016) 312-317.

13. IMO. Resolution MSC.267(85)-adoption of the international code on intact stability. London, UK : IMO Publishing, 2008.

14. F.K. Barnes, On a new method of calculating the statical and dynamical stabilities of a ship, Transactions - Society of Naval Architects. 2 (1861) 163-179.

15. W. Peters, V. Belenky, C. Bassler, K. Spyrou, N. Umeda, G. Bulian, et al., The second generation intact stability criteria: an overview of development, Transactions - Society of Naval Architects and Marine Engineers. 119 (2011) 225-264. 